ment was required and no case progressed to local abscess formation.

(c) Blockage Alone.-This occurred without evidence of inflammation in only 12 cases $(2 \%)$. Usually there was evidence that the tip of the catheter had pierced the vein wall, causing extravasation. In order to facilitate introduction of the polythene cannula into the tiny veins of the infant, the tip of the cannula is often trimmed obliquely by the surgeon, and is probably the main reason for this accident. A " sharp-pointed" cannula should therefore be rounded off before introduction.

(d) Deep Venous Thrombosis.-Generalized oedema of the cannulated limb occurred in one case only on the fourth day, and the infusion was stopped. There was only slight redness of the infused vein, and no absolute conclusions can be drawn. The infant was 5 days old, was not given anticoagulants, and recovered uneventfully.

(e) ? Septicaemia.-One four-month-old infant developed septicaemia during the forty-eight hours following a difficult reduction of an ileocolic intussusception. Intravenous fluids were given during this time and were discontinued after 36 hours. There was no obvious thrombophlebitis. Acute osteitis of two long bones ensued, and an abscess developed in the laparotomy wound. A penicillin-resistant strain of Staphylococcus aureus was cultured in the pus of all three septic foci ; with appropriate treatment the infant made a full recovery. The most probable source of infection was the wound itself, during operation, but the possibility that the organism was introduced via the infusion apparatus, although unlikely, cannot be ruled out.

\section{Conclusion}

The Heller valve provides a simple, cheap, reliable, and accurate method of giving intravenous fluids to newborn infants. Its use reduces the time spent by the medical and nursing staff in supervising intravenous drips in neonates ; and it can readily be adapted for other purposes.

Minor complications occur, as with any form of intravenous infusion in infants, but their incidence is not high, and is probably much lower than that associated with earlier techniques. In a series of 500 valve-infusions only two major complications were found which might be attributed to this method.

The valve costs $6 \mathrm{~s} .9 \mathrm{~d}$., which is little more than the cost of a single disposable drip set, and it may be used more than fifty times before leak-back occurs.

\section{Summary}

A method of administering intravenous fluids to infants is described and assessed in the light of experience of over 1,200 infusions. The advantages over more conventional methods are discussed and the possibilities of the adaptation of the system for other purposes are indicated.

The Heller valve is manufactured by Medical and Industrial Equipment Ltd., 10/12 New Cavendish Street, London, to whom I am grateful for information and advice. I am also indebted to Mr. J. Devlin for the photographs. I should like to pay tribute to the nursing staff, whose constant care and skill have contributed so much to the well-being of the infants discussed above.

\section{REFERENCES}

Auld, W., and Munro, J. R. (1962). Scot. med. F., 7, 431 Ballantine, R. I. W., and Jackson, I. (1964). Brit. med. f., 1, 1339. Brit. med. F., 1964, 1, 1201.

Graham, A. G. (1964). Brit. med. F., 2, 246.

Heller, M. H. (1958). Anaesthesia, 13, 358.

Rickham, P. P. (1959). Lancet, 1, 556.

Thomas, D. V. (1964), Brit. med. F., 1, 1635

Thomson, W. J. (1961). Anaesthesia, 16, 104

\title{
Coronary Heart Disease in the Aged
}

\author{
A. K. THOULD,* M.D., M.R.C.P.
}

Brit. med. F., 1965, 2, 1089-1093

William Heberden (1802) stated that he had seen nearly 100 people with angina pectoris, and all but four were males near or past the fiftieth year of age. We are now uncomfortably aware of the frequency with which the male members of western populations, especially the relatively young, die of coronary heart disease. The death rate from diseases of the heart is said to have changed very little in the years 1850 to 1920 , but from 1924 onwards the death rate rapidly increased until about 1952, when it showed signs of levelling off (Campbell, 1963a). This apparent and alarming increase may well be due to the possibility that those who would have died from the infectious diseases now survive longer to die from coronary heart disease, as so lucidly argued by Campbell (1963b). It is doubtful, judging by post-mortem reports, that there has been any absolute increase in the incidence or severity of atheroma over the years $1908-49$; the reverse is true if anything (Morris, 1951). There is some evidence that in the elderly the disease is different in its clinical presentation (Dreyfuss, 1959), and it is a comparative rarity to make the diagnosis of a coronary thrombosis in the age group 60-80 years (Howard and Gresham, 1961). Many of the coronary * University College Hospital, London. Now at St. Bartholomew's Hos-
pital, London. thromboses in the elderly are "silent" (Rodstein, 1956), and the distribution of the atherosclerotic lesions is different (Wright, 1960).

We were impressed by the rarity with which we saw the clinical entity of acute coronary heart disease in those admitted to an acute geriatric department serving a sizable area of North Central London. In those in whom the diagnosis was made the clinical severity of the episode was marked and the outlook grave. In this paper we present our findings in a three-year retrospective study.

\section{Methods}

The case records of all admissions to this 88-bed department over a three-year period were examined, and only those patients who had unequivocal electrocardiographic or post-mortem evidence of a recent-that is, within one week-coronary thrombosis or myocardial infarct were accepted for this study, regardless of the original reason for admission. Electrocardiographs were not taken routinely on admission of all patients, though in practice this was done in fact in a high proportion. We were, of course, aware that cardiovascular disease may present atypically in the elderly, and therefore we readily asked 
for an electrocardiograph on what would in younger age groups be regarded as slender grounds. The diagnosis of cerebrovascular accident, coronary thrombosis, or myocardial infarct refers to the diagnosis made following proper investigation after admission to the department, and was not necessarily the diagnosis on admission. It must be emphasized that admissions to this department form a highly selected group, and this study cannot therefore claim to give an accurate picture of the incidence of coronary heart disease in the elderly, but only of its presentation in our experience. We found, for instance, a rather low incidence of strokes in patients admitted to the department. For the sake of comparison the numbers of patients admitted with recent cerebrovascular accidents or with dissecting aortic aneurysm were also ascertained.

\section{Results}

Only patients aged 65 or over are accepted for admission to this department. During the three years there were 1,300 admissions (545 male and 755 female). Of these, $157(12 \%)$ were diagnosed as having had a recent cerebrovascular accident. Only one patient was found to have a dissecting aortic aneurysm. He was aged 72 and died shortly after admission. Forty-two $(3 \%)$ were found to have had a recent coronary thrombosis or myocardial infarct. None were diabetic.

\section{Strokes}

The proportion of the total admissions with a diagnosis of a cerebrovascular accident was the same for either sex-12\%. In the males $22(35 \%)$ out of 63 died, and in the females 43 $(46 \%)$ out of 94 died. However, the overall average age of the females on admission was slightly greater (78 years) than that of the males (74 years). The average age of those females who died from this disease was 79 , and the average age of the males who died was 76 .

\section{Coronary Thrombosis}

Forty-two patients (25 males, 17 females) were found to have had a recent coronary thrombosis or myocardial infarct. The percentage of all male admissions with this diagnosis was therefore $5 \%$, and of female admissions $2 \%$. The average overall age was 75 (range $65-87$ years). The average age of male survivors was 72 (range 65-78), and of female survivors 76 (range 69-87). The average age of those males who died was 75 (range 65-86), and of the females who died 76 (range 65-84). Reference to the Table shows how few survived: only $4(16 \%)$ of the males and $5(29 \%)$ of the females. Most of those who died did so within 30 days of admission: $23(70 \%)$ out of 33 .

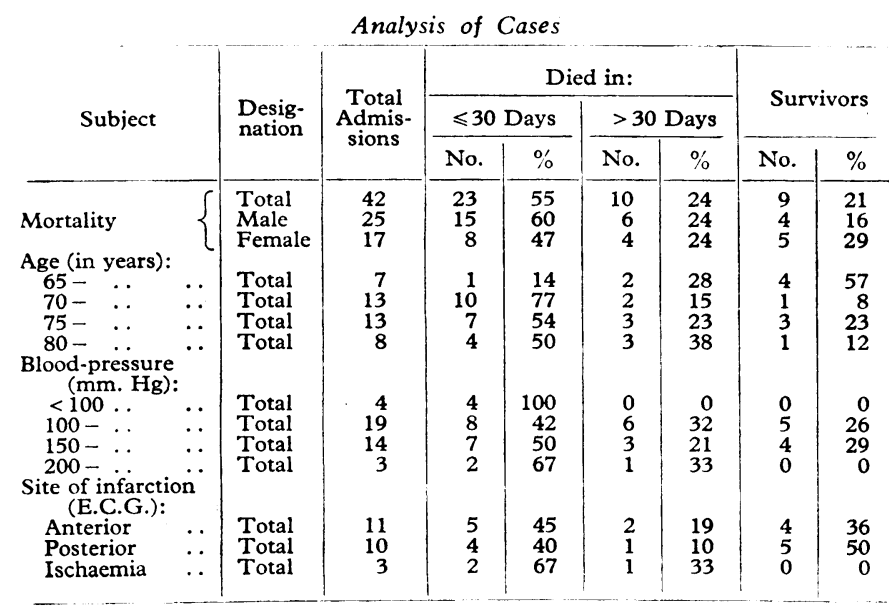

The death rate overall of all admissions in the first 30 days was therefore $55 \%$. It will be seen from Fig. 1 that a third were dead by the end of the first week. Ten died during the first day. The prognosis for females was better than that for males.

Age.-The outlook was clearly affected by age. While over half of those aged 65 to 69 survived, only $12 \%$ of those aged 80 or more lived. Fig. 2 shows that the percentage survival for females was better than that for males at almost all ages considered.

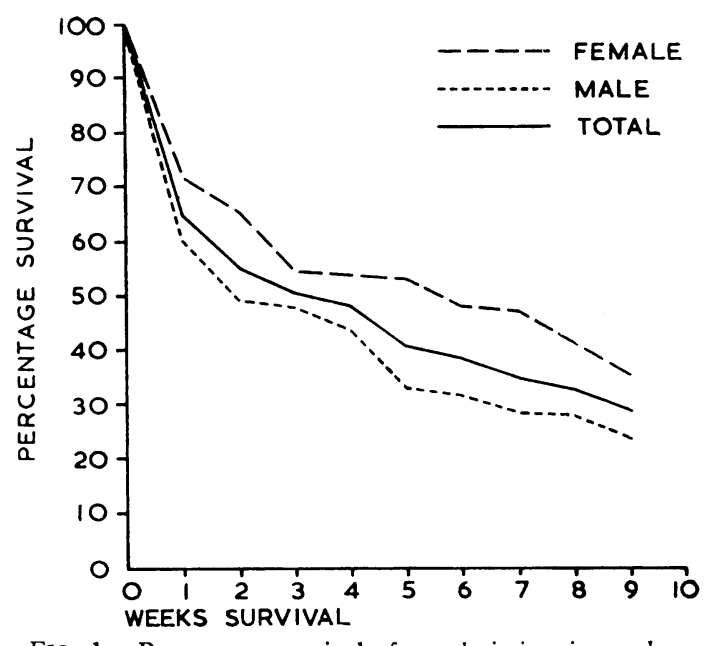

FIG. 1.-Percentage survival after admission in weeks.

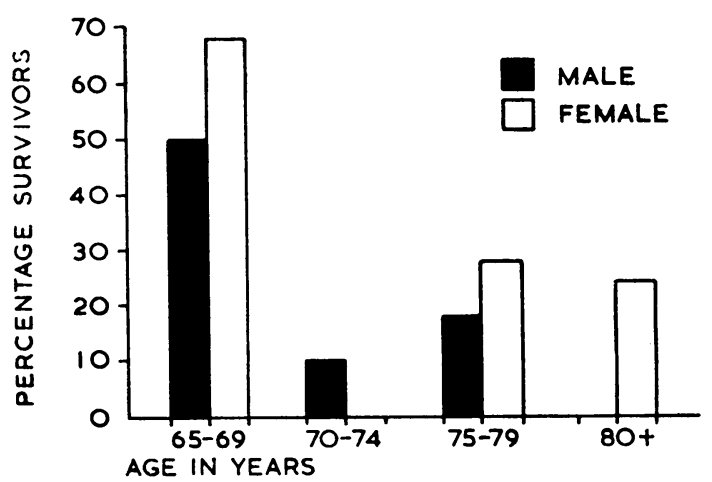

FIG. 2.-Nomogram showing percentage survival by age in decades.

Blood-pressure.-It will be seen from the Table that where the systolic blood-pressure on admission was less than $100 \mathrm{~mm}$. $\mathrm{Hg}$ the prognosis was hopeless, and it was scarcely better in those with a systolic pressure of $200 \mathrm{~mm}$. Hg or more.

Site of Infarct (Electrocardiogram).-Those with posterior infarctions seemed to fare somewhat better than those with an anterior one, but owing to the small numbers involved it would be unwise to draw firm conclusions. In three patients the E.C.G. showed the changes of ischaemia only, but this was not associated with a better prognosis.

Symptoms and Signs.- The most prominent symptoms were pain and dyspnoea. Pain was complained of by $20(48 \%)$ patients, and it was severe in seven. In $22(52 \%)$ patients the coronary thrombosis was apparently pain-free. The pain was usually retrosternal and rarely referred to the arm, but in four $(10 \%)$ it was abdominal. The presence or absence of pain had little bearing on the prognosis. Dyspnoea at rest occurred in about half, and also bore little relation to the outcome. However, where paroxysmal dyspnoea was a feature ( 3 patients) the outlook was grave, and all three died within 30 days; two in the first week. A few merely complained of tiredness, weakness, or lethargy. Others vomited, but had no significant pain. A history of strokes (6 patients) appeared to have no bearing 
on the prognosis, but where there was a history of known coronary thromboses (5 patients) the outcome was invariably fatal. Grave prognostic signs appeared to be confusion (6 patients), sudden collapse (6), rhythm change of the pulse (5), and cyanosis (13). Nearly $80 \%$ of patients with one or more of these signs died within 30 days. The presence of marked emphysema (9 patients) was also of grave import. Surprisingly, however, nearly half of those in congestive cardiac failure survived the first 30 days, and nearly one-fifth recovered. Heart failure was noted in 23 patients. Five patients were admitted in coma, and four of them died. Only one complained of angina of effort; she also had mild intermittent claudication of the calves, but she survived. Seven patients were too ill to give any account of their illness. A pericardial friction rub was heard in only one patient, and he died within a few days. Another male had obvious aortic stenosis, and he too failed to survive. A gallop rhythm was detected in four people, and three of them died. The patient's temperature on admission was a useful guide to prognosis. Where it was less than $98^{\circ} \mathrm{F}$. $\left(36.7^{\circ}\right.$ C.) (10 patients) none survived, almost all dying within a day or two. Similarly, where it was greater than $101^{\circ} \mathrm{F}$. $\left(38.3^{\circ} \mathrm{C}\right.$.) ( 3 patients) again none survived, though two lived longer than 30 days. Where the temperature was between 98 and $101^{\circ}$ F. (21 patients) one-third lived. Only three were obese, and two of them died.

Investigations. - The blood urea was recorded on admission in 16 pat'ents, and where it was greater than $100 \mathrm{mg} . / 100 \mathrm{ml}$. none survived. Below this level it had no prognostic value. The white-cell count in the peripheral blood was measured in 17 , and where it was greater than $10,000 / \mathrm{c} . \mathrm{mm}$. the prognosis was much poorer than where it was normal. Elevation of the blood sedimentation rate was of no value in assessing prognosis. A chest radiograph was obtained in 22 patients, and half of these had evidence of heart enlargement or dilatation, but this had no apparent bearing on the outcome. The serum glutamic oxaloacetic transaminase was measured in only three patients: it was elevated in all three, but two survived.

Necropsy Findings.-Post-mortem examination was carried out in $29(88 \%)$ of the 33 patients who died. A recent antemortem thrombus in a coronary artery or one of its major branches was found in 18 hearts. This involved the left coronary artery in 16 and the right coronary artery in four. Myocardial infarctions of the anterior wall of the left ventricle were seen in 19, and of the posterior wall in 7 . Recent infarctions were multiple in three patients, and associated with rupture of the ventricular wall in two (1 anterior and 1 posterior). There was a recent ante-mortem thrombus in a coronary artery without an obvious recent infarct in six hearts. Eleven patients had had both an E.C.G. and a necropsy and in $9(82 \%)$ there was good agreement regarding the site of the infarct. In the remaining two the E.C.G. showed only left bundle-branch block and ischaemia, while necropsy revealed an anterior infarct in one and a posterior infarct in the other. In one heart infarction of the right ventricle as well as the left was found. Th:s was the only example seen of right ventricular infarction. Evidence of myocardial fibrosis, usually patchy, was found in almost all the hearts, and this fibrosis was diffuse in seven. Obvious old myocardial infarcts were seen in 14 . Atheroma of the coronary arteries was observed in all. It was gross in $20(69 \%)$, extremely severe in one, mild in one, and moderate in the rest. There was usually extensive calcification in the media of the coronary arteries, and total occlusion of a coronary artery by old thrombus was seen in two hearts. The coronary ostia were severely stenosed in one patient who was known to have had a positive serological test for syphilis. Atheroma of the aorta was described as moderate in nine, mild in two, severe in 10, and gross in one. Moderate atheroma of the pulmonary arteries was seen in two. Atheroma of the cerebral arteries was mild in two, moderate in one, and severe in nine. There were areas of softening of the brain in six patients and cerebral cortical atrophy in seven others. Fourteen were found to have pulmonary oedema, and seven to have a pleural effusion. Pulmonary infarcts were observed in three. There was a pericardial effusion in three patients, left ventricular hypertrophy in 12 (gross in two), and right ventricular hypertrophy in two. One patient had aortic stenosis. Other findings were cirrhosis of the liver (1), Hashimoto's thyroiditis (1), and syphilitic aortitis (2). Two patients (both males) had a carcinoma of the bronchus, and one of them also had a hypernephroma of the kidney.

Treatment.-Anticoagulants were not used in this age group. Treatment was confined to the usual procedures for the management of pain, heart failure, and shock. Those who were fit enough were encouraged to sit out of bed as soon as possible.

Occupation.-In almost all instances these patients were drawn from social classes IV and V.

\section{Illustrative Case Histories}

Case 1.-A man aged 86 was admitted to hospital complaining of feeling very tired. His temperature on admission was $95^{\circ} \mathrm{F}$. $\left(35^{\circ}\right.$ C.) and he was cyanosed and dyspnoeic. His blood-pressure was unrecordable. There was no previous history of myocardial infarction, and he had previously been in good health. He died the day after admission, and post-mortem examination revealed pulmonary oedema, severe coronary and aortic atherosclerosis, and a recent infarct of the posterior wall of the left ventricle which also involved the septum.

Case 27.-A woman aged 79 was admitted with a four-days history of chest pain and dyspnoea. She was found to be in heart failure with bilateral pleural effusions. Her blood urea on admission was $64 \mathrm{mg} . / 100 \mathrm{ml}$., her E.S.R. was $36 \mathrm{~mm}$. in the first hour (Westergren), and her temperature and white-cell count were normal. Her E.C.G. showed a recent posterior myocardial infarct. She made a good recovery.

Case 29.-A man aged 80 was admitted with a history of pain and tightness in the chest five days previously. He was obese and in heart failure, with moderately severe emphysema. There was a history of a previous myocardial infarct a year before. His temperature on admission was $98^{\circ} \mathrm{F} .\left(36.7^{\circ} \mathrm{C}\right.$.) and his blood-pressure $105 / 55 \mathrm{~mm}$. Hg. The E.C.G. was suggestive of an anteroseptal infarct. He died two days later, and post-mortem examination showed infarction of the anterior wall of the left ventricle, also involving the septum. Left ventricular hypertrophy, pulmonary oedema, and a pleural effusion were found. The coronary arteries were atheromatous and there was an occlusion of the interventricular branch with ante-mortem thrombus $1.5 \mathrm{~cm}$. from its origin.

\section{Discussion}

The diagnosis of recent coronary thrombosis or myocardial infarction was found to be only a quarter as common as that of a cerebrovascular accident as a reason for admission. There was little difference in the average ages of the males and females admitted because of coronary heart disease. Those admitted form, of course, a highly selected group, and this study can have no pretensions to giving an accurate picture of the relative incidence of coronary thromboses or myocardal infarcts in the elderly compared with other diseases, such as cerebrovascular accidents. It does, however, make the point that coronary heart disease is an uncommon cause of admission to hospital in this age group. One can only speculate on the reasons for this. In those aged 65 or more the mortality from coronary heart disease is high. Russek et al. (1951) found it to be $40 \%$ in those aged more than 60 and $60 \%$ in those who were a poor risk. This increase in mortality in the aged appears to be due to a higher incidence of more severe attacks. In consequence, many presumably die without ever reaching hospital.

In the Framlingham study $45 \%$ of all patients with coronary thromboses never reached hospital for one reason or another. Half of them died suddenly, and a quarter had painless infarctions (Kannel et al., 1961). In the present series the incidence 
of painless infarction was $52 \%$. Snow et al. (1956) found an incidence of painless infarction of $36 \%$, and po nt out that in the literature estimates of this vary from 1 to $61 \%$. Papp (1952) stated that in his view the distress of heart failure may overshadow the pain. Only $5(22 \%)$ of the 23 of our patients who were in heart failure complained of pain. Presumably, therefore, many of the elderly do not complain of this symptom when they develop a coronary thrombosis and do not contact their doctors. Others suddenly develop heart failure and are treated at home. Many will die before a doctor can be called. Cerebrovascular accidents tend to be more obvious and dramatic to the layman, and less easy for relatives to cope with, and these patients are more likely to be admitted to hospital.

The mortality in those admitted with a diagnosis of coronary thrombosis or myocardial infarct was $55 \%$ in the first 30 days, and the overall mortality was $79 \%$. These figures are comparable to those quoted by Russek et al. (1951). The males fared somewhat worse $(84 \%$ eventually died from their coronary heart diseases) than the females, of whom $71 \%$ eventually died. The mortality rises fairly steeply with age, and this is clearly seen by reference to the Table. A high systolic blood-pressure affected the prognosis quite markedly, in contrast to the findings of Droller and Pemberton (1953) in this age group. A significant fall in blood-pressure occurred in only four, and all four died. The overall pattern of symptoms and signs was similar to that described by Rodstein (1956) in this age group, with the exception that there was a much higher incidence of heart failure. The presence of heart failure did not seem to worsen the prognos:s. Bedford and Caird (1956) noted that elderly folk with heart failure progressed surprisingly well, though those with hypertension in addition did not have such a favourable outlook. A high incidence of cardiac enlargement $(38 \%)$ as seen on a chest radiograph was observed by Brown et al. (1957) in this age group, and in the present series it was found that half of those who had had a chest radiograph taken had enlargement of the heart shadow.

In those aged 65 or more the pattern of coronary heart disease has been noted by many observers to be different. Painter et al. (1960), in their study of a North Dakota community, found an age difference of approximately 10 years in the average age of younger male and female survivors of myocardial infarcts. The female survivors were older than the males, though this age difference had disappeared by the ninth decade. In the present series little difference was found in the average age of the male and female survivors. Painter et al. (1960) observed that in the younger age groups those who survived the first 24 hours had a three-to-one chance of survival. This is not true of the elderly. Morris et al. (1957) found the proportion who survived the first month decreased considerably with age. In the present series 32 patients survived the first day, but a further 23 died without leaving hospital: all but three died within nine weeks of admission. In other words, the chances of survival in those who survived the first day were over four to one against.

The older patients tend to have more severe attacks (Russek et al., 1951). These workers suggested that the absence of severe atheroscleros's of the coronary vessels may be a prerequisite to the attainment of old age. However, we found gross coronary atheroma in $69 \%$. In the young, males are much more often affected by coronary heart disease than females, though this is much less apparent by the eighth decade (Peel, 1955). Peel also found that the expectation of life in those with coronary heart disease diminished rapidly after the age of 55. We still found that the incidence of admissions due to this disease in the elderly was twice as great in males as in females. What seems to distinguish the younger from the older age groups is not so much the nature as the distribution of the lesions (Wright, 1960). In the younger groups the pathological changes are confined to the heart, but in the elderly it is part of a generalized atherosclerosis. We certainly found good evidence of significant atherosclerosis in the cerebral vessels and the aorta.

In a study of young men killed in flying accidents (Mason, 1963) a sign ficant association was found between age and severity of coronary heart disease. Myocardial fibrosis was not a feature, though young men of similar ages dying from coronary heart disease do have some evidence of it. However, completely unheralded fatal coronary occlusion is commoner in younger age groups (Yater et al., 1951). Weitzman and Smith (1959) injected the coronary arteries with radio-opaque dye in symptomless males dying of other causes at 50 to 69 years of age. They found an increased anastomotic pattern with a subendocardial plexus of vessels. Fulton (1956), in similar studies in males in the seventh and eighth decades, also found an anastomotic development in the inner zone of the left ventricle, filled from both coronary arteries. There were scattered areas of focal necrosis. He concluded that in these elderly patients occlusion of major branches of the coronary arteries can occur without infarction. There were six such instances in the present study.

From my experience I conclude that, in the elderly, coronary heart disease is an uncommon reason for admission to hospital, and that though the male predominance over the female with this disease is less obvious, it is still appreciable. The outlook in those admitted to hospital is poor, though somewhat better in females, and the prognosis worsens sharply with age. Atherosclerosis of the coronary arteries is accompanied by evidence of widespread arterial disease, and we have noted that a history of previous myocardial infarct ons is of grave significance. Coronary artery occlusion without evidence of recent myocardial infarction would seem to occur, though it is not common. The electrocardiogram is surprisingly accurate in my experience, though others have not found it so (Woods et al., 1963). Treatment is largely symptomatic, and is mainly directed towards heart failure, shock, and pain where these are present. This is in reasonably good agreement with the findings of other observers. I agree that there are s: gnificant differences in the pattern of coronary heart disease in the elderly compared with the younger age groups. No reliable history of the patients' smoking habits was available. Acheson and Jessop (1961) found no relation between smoking and coronary heart disease in those aged more than 65 years.

\section{Summary}

The findings of a three-year retrospective study of patients aged 65 years or older admitted to an acute geriatric department because of coronary heart disease are presented. They formed only $3 \%$ of a total of 1,300 admissions, and $33(79 \%)$ out of 42 died. The prognosis was somewhat better for females than for males. Over half did not complain of pain. Heart failure was noted in 23 of them. The differences between coronary heart disease in the elderly and the young are discussed.

I would like to thank the Lord Amulree for permission to present details of these patients admitted under his care, and for his kindness and help in the presentation of this paper. I also wish to thank Mr. M. P. Curwen, of the Statistical Department, St. Bartholomew's Hospital, for his advice.

\section{REFERENCES}

Acheson, R. M., and Jessop, W. J. E. (1961). Brit. med. F., 2, 1108. Bedford, P. D., and Caird, F. I. (1956). Quart. F. Med., 25, 407. Brown, R. G., Davidson, L. A. G., McKeown, T., and Whitfield, A. G. W. (1957). Lancet, 2, 1073 Campbell, M. (1963a). Brit. med. F., 2, 528. (1963b). Ibid., 2, 712 .

Dreyfuss, F. (1959). Amer. F. Cardiol., 3, 590.

Droller, H., and Pemberton, J. (1953). Brit. Heart f., 15, 199.

Fulton, W. F. M. (1956). Ibid., 18, 341.

Heberden, W. (1802). Commentaries, p. 365. London. 
Howard, A. N., and Gresham, G. A. (1961). Lancet, 1, 397. Kannel, W. B., Dawber, T. R., Kagan, A., Revotski, N., and Stokes, J.,

Mason, J. K. (1963). Brit. med. f., 2, 1234

Morris, J. N. (1951). Lancet, 1, 69.

Peady, J. A., and Barley, R. G. (1957). Brit. Heart f., 19, 227.

Painter, R. C., Ralston, L. S., Fawcett, R. M., Zukel, W. J., and Lewis, R. H. (1960). f. Amer. med. Ass., 172, 1261.

Papp, C. (1952). Brit. Heart f., 14, 250.

Peel, A. A. F. (1955). Ibid., 17, 319.
Rodstein, M. (1956). Arch. intern. Med., 98, 84.

Russek, H. I., Zohman, B. L., Doerner, A. A., Russek, A. S., and White, L. G. (1951). ₹. Amer. med. Ass., 147, 1731.

Snow, P. J. D., Morgan Jones, A., and Daber, K. S. (1956). Brit. Hear f., 18, 435 .

Weitzman, D., and Smith, E. B. (1959). Brit. med. F., 2, 162.

Woods, J. D., Laurie, W., and Smith, W. G. (1963). Lancet, 2, 265.

Wright, H. B. (1960). Ibid., 2, 980.

Yater, W. M., Welsh, P. P., Stapleton, J. F., and Clark, M. L. (1951) Ann. intern. Med., 34, 352.

\title{
Five Weeks to Escape the Sleeping-pill Habit
}

\author{
IAN OSWALD,* M.A., M.D., D.SC., D.P.M. ; ROBERT G. PRIEST, $\dagger$ M.B., B.S., M.R.C.P.ED., D.P.M.
}

Brit. med. F., 1965, 2, 1093-1095

Ten per cent. of all National Health general practitioners' prescriptions are for hypnotic drugs (Ministry of Health, 1964). Large quantities of these drugs lie around in the average home. In Edinburgh hospital admissions for self-poisoning by barbiturates and non-barbiturate sedatives have increased fivefold in 10 years, though the death rate from suicide has fluctuated little (Kessel, 1965).

Belleville and Fraser (1957) reported that nurses' assessments of sleep revealed some tolerance to barbiturate hypnotics within the first 10 days, and tolerance apparently complete after three months. It is common for patients to describe taking sleepingpills for many years, of ten since an hospital admission for some minor procedure. Many will say they have tried to stop but found themselves unable to sleep "properly" without the accustomed hypnotic.

Persons taking very large amounts of barbiturates are liable to convulsions, delirium, insomnia, and other symptoms if their drugs are suddenly withdrawn. These features occur especially in the first week but can continue for two weeks (Fraser et al., 1964 ; Wulff, 1959).

In a previous investigation recent developments in knowledge of normal sleep were utilized to measure some neurophysiological functions after withdrawal of amphetamine from addicts. Return to normal took up to two months (Oswald and Thacore, 1963). Similar techniques have been used in the present study.

\section{Indices Measured}

It is now known that there are two kinds of sleep with sharply differing physiological characteristics (Jouvet, 1965). They alternate abruptly during the night. Initially humans always pass into the orthodox phase of sleep ("slow-wave" or "forebrain" phase) without rapid eye-movements but with electroencephalographic slow waves and "sleep spindles." After not less than 45 minutes (Oswald and Thacore, 1963; Rechtschaffen and Verdone, 1964), usually an hour or more, a sudden transition takes place to the paradoxical phase of sleep (" hind-brain," " rapid eye-movement," or "low voltage fast" sleep) when the E.E.G. is of low voltage and rapid jerky eyemovements occur. The paradoxical phase, with small but consistent individual variations, usually occupies just under $25 \%$ of the total night's sleep (Oswald et al., 1963; Rechtschaffen and Verdone, 1964 ; Williams, R. L., et al., 1964), but it occupies less than 35 minutes in the first two hours.

\footnotetext{
* Visiting Professor of Psychiatry, University of Western Australia,

Nedlands, Western Australia.
+ Lecturer in Psychiatry, University of Edinburgh.

Volunteers have been used as their own controls. All-night recordings of their E.E.G. and eye-movements have been made, though, as in the previous study (Oswald and Thacore, 1963), it is obvious in retrospect that recording of only the first two hours of sleep would have revealed the essential information. Recordings ran to some 35 miles $(56 \mathrm{~km}$.) of paper. Measurements made have again been of $(a)$ the delay between sleep onset (first E.E.G. "sleep spindles") and the first rapid eyemovements of the first paradoxical sleep of the night, $(b)$ the number of minutes of paradoxical sleep in the first two hours of sleep, and $(c)$ the total number of minutes of sleep and the total number of minutes of paradoxical sleep in the whole night. The last values have been combined for the pair of volunteers concerned to give the percentages of paradoxical sleep in the combined whole night shown in Figs. 1 and 2.

Volunteers were paid, and throughout the whole period of the experiments undertook to avoid late nights, alcohol, or other excesses. They were young adult normal males previously known to us and used in past studies.

\section{Experiment 1}

Two volunteers were used. After five baseline nights of sleep, for 14 consecutive nights they received $15 \mathrm{mg}$. of Mogadon

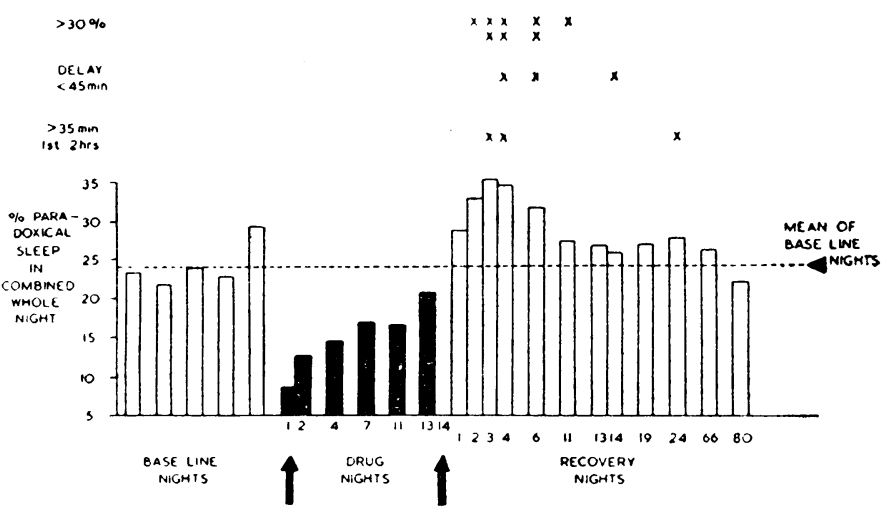

Fig. 1.-Effect of $15 \mathrm{mg}$. of Mogadon on the sleep of two men. When the drug is given each night the proportion of the night spent in paradoxical sleep (vertical columns) is decreased but then slowly rises. Withdrawal of drug causes a rise to ahnormal levels, maximal on the Withdrawal of drug causes a rise to ahnormal levels, maximal on the
third night. The time scale is not linear. Where either or both volunteers spent over $30 \%$ of the whole night in paradoxical sleep, had a delay period of less than 45 minutes between first falling asleep and first rapid eye-movements of paradoxical sleep, or spent more than 35 minutes of the first two hours of sleep in paradoxical sleep, a star has been placed over the night concerned. It will be seen that values beyond these criteria occurred only between the second and twenty-fourth recovery nights. 